\title{
DETERMINANTES DO CRESCIMENTO ECONÓMICO EM PORTUGAL: UMA ABORDAGEM SECTORIAL PARA A REGIÃO DO ALGARVE
}

\author{
DETERMINING FACTORS OF ECONOMIC GROWTH IN PORTUGAL: A SECTOR-BASED APPROACH \\ FOR THE ALGARVE REGION \\ DETERMINANTES DEL CRECIMIENTO ECONÓMICO EN PORTUGAL: UN ABORDAJE SECTORIAL \\ PARA LA REGIÓN DEL ALGARVE
}

Jorge M. Andraz*

João Albino Silva**

Carlos Manuel Viegas***

* Faculdade de Economia, Universidade do Algarve, Portugal e CEFAGE- Center for Advanced Studies in Management and Economics, Universidade e Évora, Portugal. E-mail: jandraz@ualg.pt.

** Faculdade de Economia, Universidade do Algarve, Portugal e CIEO - Centre for Spacial and Organizacional Dynamics, Universidade do Algarve, Portugal. E-mail: jsilva@ualg.pt.

***Mestre em Gestão e Desenvolvimento em Turismo, Universidade do Algarve, Portugal. E-mail: carlosgviegas@iol.pt.

\section{RESUMO}

Este trabalho procura identificar os sectores de actividade que estiveram na base do crescimento económico da região do Algarve, a região sul de Portugal continental, bem como os estímulos de crescimento que conseguiram transmitir aos sectores endógenos da região no período entre 1995 e 2003. Com a adopção do modelo de Base Económica, aos níveis inter-regional e intra-regional, os resultados sugerem que foram os ramos directamente e indirectamente ligados ao turismo, como o Alojamento e Restauração, a Pesca, o Comércio e a Construção que constituíram o motor de crescimento da região. Contudo se registou uma redução do grau de indução destes ramos sobre as actividades não básicas da região. A análise demonstra que a economia regional é bastante tercearizada e o emprego básico encontra-se essencialmente nos concelhos com freguesias litorais, entre as cidades de Lagos e Faro, que possuem uma estrutura económica directamente ligada ao turismo através do ramo do Alojamento e da Restauração e indirectamente, através dos ramos do Imobiliário e Alugueres e do Comércio e Outros.

PALAVRAS-CHAVE: Turismo. Emprego. Algarve. Sectores básicos. Sectores não básicos.

\section{ABSTRACT}

This paper identifies the economic sectors that formed the basis of the economic growth observed in the Algarve region in the south of Portugal, and the factors that contributed to the dynamism of endogenous sectors of the region between 1995 and 2003. By applying the Model of Economic Basis at inter- and intraregional levels, the results indicate that the sectors directly and indirectly related to tourism, such as Hotels and Restaurants, Fishery, Commerce and Construction sectors, were the ones that formed the basis of the region's economic growth. However, a reduction in the level of induction of these sectors on the non-basic activities of the region was observed. An analysis showed that the region's economy 
is heavily dominated by the services sector, and that basic employment is mostly concentrated in the coastal regions, between the areas of Lagos and Faro, these being the areas whose economies are directly related to tourism, whether through the Hotels and Restaurants sector, or indirectly, through Real Estate, Property Rentals, Commerce, and others.

KEYWORDS: Tourism. Employment. Algarve. Basic sectors. Non-basic sectors.

\section{RESUMEN}

Este trabajo intenta identificar los sectores de actividad que estuvieron en la base del crecimiento económico de la región del Algarve, en la región sur del Portugal continental, así como los estímulos de crecimiento que lograron transmitir a los sectores endógenos de la región en el período de 1995 a 2003. Con la adopción del modelo de Base Económica a niveles interregional e intrarregional, los resultados sugieren que fueron los ramos directa e indirectamente relacionados al turismo, tales como el Alojamiento y Restauración, la Pesca, el Comercio y la Construcción, los que constituyeron el motor de crecimiento de la región. Aún así, se registró una reducción en el grado de inducción de estos ramos sobre las actividades no básicas de la región. El análisis demuestra que la economía regional está bastante tercerizada y el empleo básico se encuentra esencialmente en los Ayuntamientos litorales, entre las ciudades de Lagos y Faro, que poseen una estructura económica directamente relacionada al turismo a través del ramo del Alojamiento y de la Restauración e indirectamente, a través de los ramos Inmobiliario y Alquileres y del Comercio, entre otros.

PALABRAS CLAVE: Turismo. Empleo. Algarve. Sectores básicos. Sectores no básicos.

\section{INTRODUÇÃO}

A economia portuguesa, à semelhança das suas congéneres europeias, é uma economia aberta, sujeita a fortes influências externas, tais como as que resultam das flutuações da procura externa dos seus produtos e serviços. Ao nível das regiões, individualmente consideradas e com estruturas económicas pouco diversificadas, a questão da vulnerabilidade às pressões externas coloca-se com uma maior acuidade. É neste contexto que se insere a região do Algarve, a qual tem vindo a afirmar-se crescentemente como destino turístico de excelência, sendo responsável por $38 \%$ da oferta turística, em termos de números de camas e por uma procura turística que absorve $22 \%$ das dormidas nos estabelecimentos hoteleiros em Portugal (Instituto Nacional de Estatística, 2004). Em termos económicos, o turismo representa para a região, directa e indirectamente, cerca de $66 \%$ do PIB regional e a ocupação de aproximadamente $60 \%$ da população activa (World Travel \& Tourism Council, 2003). Verifica-se que mais de $50 \%$ do valor acrescentado na região é gerado por quatro ramos, nomeadamente, os ramos do Comércio e Outros com $17.3 \%$, do Alojamento e Restauração com $15.4 \%$, do Imobiliário e Alugueres com $12.8 \%$ e dos Transportes e Comunicações com $8.1 \%$. Estes ramos configuram, portanto, o núcleo dos principais criadores de riqueza na região, e possuem coeficientes de intensidade das exportações relativamente elevados.

A actividade turística apresenta também fortes ligações a outros ramos de actividade, como sejam o Comércio, o Alojamento e Restauração, o Imobiliário e Alugueres e os Transportes e Comunicações e a maior fatia dos recursos gerados pela região destinou-se ao consumo privado, onde os não residentes têm um forte peso. A procura dos não residentes é satisfeita em $61 \%$ pelo ramo do Alojamento e Restauração e em $20 \%$ pelas Indústrias Transformadoras, o que os torna nos ramos mais directamente ligados às actividades turísticas na região. Os seus principais fornecedores são, para além da própria Indústria Transformadora e Alojamento e Restauração, o Imobiliário e Alugueres, a Electricidade, Gás e Água, a Agricultura, as Actividades Financeiras, os Transportes e Comunicações, os Outros Serviços, o Comércio e Outros, e a Pesca, ou seja, são os ramos indirectamente mais ligados ao turismo na região, o que demonstra a transversalidade das actividades turísticas (CIDER e CCDR Algarve, 2001). 
No contexto desta estrutura económica, o Algarve tem registado taxas de crescimento bastante elevadas, face à média nacional. Contudo, importa identificar os ramos que estiveram na base desse crescimento, nomeadamente se estão ligados directa ou indirectamente ao turismo, a sua localização e se conseguiram transmitir efeitos de estímulo aos sectores endógenos da economia. Tal possibilidade consiste motivo de preocupação dos agentes políticos pois configuraria uma situação de crescimento pouco sustentável da região, fortemente dependente do exterior e por conseguinte extremamente vulnerável às flutuações cíclicas externas e a inexistência de estudos aplicados sobre esta problemática focalizando a região do Algarve $^{1}$, abre uma janela de oportunidade para o presente trabalho de investigação.

Nesta problemática dos fatores de dinamismo regional, as exportações exercem importantes efeitos de encadeamento sobre as atividades locais, mas não são as únicas variáveis a explicar o maior ou menor crescimento regional. Com a diversificação económica, surgem naturalmente atividades que expandem o nível de rendimento e o emprego, variáveis estas que, em conjunto, com as exportações, formam a base económica regional.

Atualmente, para estudar uma região, um dos problemas fundamentais é entender as suas relações com o restante território nacional e com o exterior, pois os ganhos com as exportações são fundamentais para a satisfação das necessidades internas e cobrir os fastos com as importações. A teoria da base económica ou base de exportação atribui precisamente às atividades de exportação - básicas - um papel estratégico e motor no desenvolvimento regional (HOYT, 1939; NORTH, 1955; TIEBOUT, 1956). Desta forma, o volume de produção e de emprego de uma região depende das suas atividades de exportação as quais induzem, através de mecanismos de interdependência na produção e no consumo, o crescimento do emprego e do rendimento das atividades a montante e das atividades orientadas para a satisfação das necessidades de consumo da população.

Em termos gerais, o modelo teórico-conceptual ${ }^{2}$ assenta na ideia de que os bens e serviços produzidos no sector básico são consumidos no exterior, dependendo do nível de rendimento do resto do mundo. Ou seja, a região pode crescer mesmo que uma grande percentagem da população não tenha poder de compra em expansão. Isto apenas é possível se a estrutura da produção se for adaptando ao crescimento do rendimento per capita do resto do mundo e não à procura interna. Assim, a população deverá importar uma variedade crescente de bens e serviços (principalmente tecnologia), para fazer face às necessidades da procura interna. O sector básico apresentará maior dinamismo de crescimento e o sector de mercado local terá o seu crescimento limitado pela distribuição do rendimento e pelas interdependências que poderão aparecer com as exportações e as atividades de mercado interno.

Ao importar cada vez mais tecnologia, a região passa a ter uma rede industrial relativamente avançada. À medida que o processo de industrialização acelera, as exportações deixam de ser a maior explicação da formação do rendimento interno. Surgem novas variáveis como o investimento nas atividades locais e construções residenciais. Assim, deve-se fazer a distinção entre base económica e base exportação. Enquanto o segundo termo só se refere às exportações, o primeiro engloba não só as exportações mas também as restantes variáveis que explicam o nível do produto local. Por outro lado, a relevância do setor exportador decorre do facto de o emprego na indústria local tender a manter uma certa proporção com o emprego na indústria básica. Dessa maneira, se as exportações são bastante rentáveis, as atividades desenvolvidas localmente serão contaminadas por este efeito positivo e poderão se expandir na medida que a atividade básica se expande. Uma vez que ocorre o sucesso da atividade básica, novas inversões serão feitas no sector, e terão como resultado não apenas o aumento do emprego no sector exportador, mas também o aumento do emprego nas atividades locais.

Um ponto a ser destacado é o de que a utilidade económica de uma região se apoia na sua especialização. Além disso, a base económica deve ser a principal fonte de explicação para o crescimento de uma região, uma vez que a influência da oportunidade económica, devido às vantagens comparativas de uma região na produção de determinados bens e serviços, foi o principal fator das taxas diferenciais de crescimento de diferentes regiões.

1 Os estudos conhecidos apresentam-se com outros objectivos ou aplicados a outras regiões (veja-se, por exemplo, Cabral e Sousa, 2001; Carvalho, 1992; Delgado et al., 2002; e Silva e Andraz, 2004).

2 Os autores agradecem os cometários de um revisor anónimo que muito contribuíram para clarificação do modelo teórico-conceptual subjacente ao modelo de base económica. 
De acordo com Zucatto et al. (1999), o modelo de desenvolvimento ideal é aquele que se fundamenta na combinação da expansão rápida das exportações, com substituições seletivas de importações, proporcionando transferência de tecnologia e diversificando interdependências entre as atividades económicas.

As atividades locais, que correspondem ao produto regional consumido pela população da região, identificam-se com a indústria tradicional, o comércio e os serviços urbanos. São atividades necessárias tanto à população como às atividades exportadoras.

A teoria da base admite, implicitamente, que no início do processo, a região possui um volume de produção que satisfaz plenamente as necessidades da população local e às empresas exportadoras e que há desemprego de fatores. Não havendo capacidade ociosa, a expansão das exportações ocasionará o deslocamento de recursos produtivos do setor de mercado interno para o setor exportador, não exercendo efeito positivo na expansão do produto regional. Ao contrário, havendo capacidade ociosa, a expansão das exportações engendrará um efeito multiplicador sobre as atividades de mercado interno e o produto regional crescerá mais do que proporcionalmente ao crescimento original das exportações.

Na medida em que o modelo assenta na importância da procura externa no desenvolvimento de cada região, enquanto elemento catalisador dos níveis de emprego e de rendimento regionais, permite identificar os ramos que estão na base do crescimento da economia. Permite igualmente identificar a sensibilidade da procura dos produtos da região face aos impactos externos sobre a economia da região através do multiplicador da base, afigurando-se, desta forma, como um importante contributo para a análise das questões centrais deste artigo.

$\mathrm{O}$ artigo encontra-se estruturado da seguinte forma. A secção 2 descreve a metodologia adoptada. A secção 3 apresenta os dados utilizados. A secção 4 apresenta os resultados empíricos e, finalmente, a seç̧ão 5 apresenta as principais conclusões.

\section{ENQUADRAMENTO METODOLÓGICO}

O modelo da base económica regional enquadra-se numa economia dual, formada por dois ramos distintos: o ramo exógeno, que compreende as actividades básicas, e o ramo endógeno, que compreende as actividades de suporte ou não básicas. O fenómeno constituído pelo ramo exportador, básico ou exógeno, compreende o conjunto de actividades produtoras de bens e serviços que se destinam a satisfazer necessidades externas à região e é encarado como o motor de crescimento da região. Por sua vez, o ramo endógeno engloba as actividades produtoras de bens e serviços destinados a satisfazer a procura interna da região, ou seja, a procura gerada pela população residente e pelas actividades complementares do ramo exportador.

Separar a região em duas áreas distintas de actividade económica é conceptualmente fácil, mas bastante difícil na prática, porque só é possível identificar inequivocamente os bens ou serviços que são apenas exportados ou apenas consumidos no interior da região. Contudo, a maioria dos bens destina-se a ambos os mercados, servindo simultaneamente clientes locais e clientes externos. Para ultrapassar esta dificuldade, recorre-se a um método indirecto de determinação da base económica que permite estimar as exportações regionais, apresentado em Costa et al. (2002), a partir do cálculo do quociente de localização $(Q L)^{3}$, o qual assume um valor superior ou inferior à unidade, conforme o ramo de actividade $i$, da região em análise, é um ramo exportador ou básico (exporta a totalidade ou parte da sua produção), ou um ramo não básico.

Com efeito, considerando o emprego como a variável em análise, o emprego básico e o emprego não básico são dados, respectivamente, por:

$$
E B_{i}=E_{i}-E\left(\frac{N_{i}}{N}\right), \forall_{i} \quad \text { e } \quad E L_{i}=E\left(\frac{N_{i}}{N}\right)
$$

onde, $N_{i}$ representa o emprego no sector ${ }^{i} ; N$ representa o emprego nacional, $\operatorname{com} N=\sum N_{i} ; E_{i}$ representa o emprego regional no ramo ${ }^{i} ; \mathrm{e}, E$ representa o emprego regional total, $\operatorname{com} E=\sum E_{i}$.

3 A utilização do quociente de localização na determinação das exportações do ramo exógeno tem subjacente alguns pressupostos. Para informação complementar, veja-se Costa et al. (2002). 
Uma das aplicações do modelo é avaliar os impactos, sobre a economia regional, de choques exógenos que vão afectar a procura dos seus produtos, através do conceito de multiplicador da base que é representado através da seguinte equação:

$$
K=\frac{1}{1-\frac{\Delta E}{\Delta E}}
$$

O indicador assume como valor mínimo a unidade, o qual corresponde a uma situação em que acréscimo da procura local associado à expansão das exportações é totalmente satisfeito pelas importações. Consequentemente, quanto maior o acréscimo do emprego não básico, gerado por uma unidade adicional do emprego total induzida pelo crescimento do emprego básico, menor será o nível total de fugas para o exterior da região e logo maior será o valor do multiplicador. Ou seja, quando maior a capacidade de criação de empregos da actividade básica sobre a não básica, maior será a propensão marginal à criação de empregos não básicos e maiores serão os efeitos multiplicadores.

\section{DADOS: DESCRIÇÃO, FONTES E ANÁLISE PRELIMINAR}

São utilizados os dados anuais do emprego no período 1995-2003, por NUTS II ${ }^{4}$, que têm por base as contas regionais publicadas pelo Instituto Nacional de Estatística (INE), que utilizam a classificação $A 17^{5}$ e dados dos concelhos da região do Algarve, que têm como fonte os censos de 2001.

O Quadro 1 revela que a região de Lisboa e Vale do Tejo surge na primeira posição com 35,8\% do emprego nacional, seguida muito perto pela região Norte, com 34,4\%. Relativamente distanciadas surgem a região Centro, com 16,7\%, o Alentejo, com 4,5\%, o Algarve, com 3,6\%, a Madeira, com $2,5 \%$ e os Açores, com 2,2\%.

Por sua vez, a análise da distribuição sectorial do emprego por regiões, apresentada no Quadro 2, revela um peso elevado da Agricultura (A) na estrutura económica do Alentejo, do Centro e das ilhas. Nas regiões Norte e Centro, a Indústria Transformadora (D) é o ramo com maior peso na economia das respectivas regiões e o Comércio e Outros $(G)$ assume-se como o maior empregador nas regiões do Algarve e de Lisboa e Vale do Tejo. O ramo do Alojamento e Restauração $(H)$ tem maior peso nas economias do Algarve e da Madeira.

A centralidade económica da região do Algarve no turismo é uma ideia comummente aceite. O recurso "sol e praia" é o seu principal elemento de atracção, embora outros produtos turísticos tenham contribuído para a diversificação da oferta turística algarvia, nomeadamente, o golfe, o desporto aventura, o turismo de negócios e o turismo de natureza, este particularmente associado ao interior da região. Tal contexto económico explica o peso de ramos como o Comércio e Outros ( $G)$, a Construção (F), o Alojamento e Restauração (H) e mesmo a Agricultura (A) na estrutura do emprego na região, já que se tratam de ramos que estão directamente e indirectamente ligados às actividades turísticas na região ou tendem a desenvolver-se à volta do ramo mais directamente ligado ao turismo como é o caso do ramo da Construção (F). O ramo das Pescas (B), que embora não tenha a importância de outrora continua a ser uma fonte para algumas comunidades locais.

4 A utilização de um maior nível de desagregação, por NUTS III, debater-se-ia com problemas de inexistência de dados estatísticos.

5 A escolha do período de análise entre 1995 e 2003 deveu-se ao facto de não ter sido possível usar uma base de dados maior porque a base utilizada entre 1988 e 1994, a NCN86 (nomenclatura dos ramos de actividade das contas nacionais portuguesas que representa a divisão da economia em 49 ramos de actividade segundo a base 86 ), não tem uma correspondência biunívoca com a classificação A17. 
Quadro 1: Frequências relativas da distribuição espacial do emprego por ramos de actividade no período 1995-2003

\begin{tabular}{|c|c|c|c|c|c|c|c|}
\hline \multirow{2}{*}{ Ramos } & \multicolumn{7}{|c|}{ Regiões } \\
\hline & Norte & Centro & L.V. Tejo & Alentejo & Algarve & Açores & Madeira \\
\hline$A$ & 34,6 & 26,1 & 15,5 & 8,2 & 6,2 & 5,6 & 3,7 \\
\hline$B$ & 23,2 & 10,5 & 18,2 & 5,7 & 24,1 & 14,1 & 4,3 \\
\hline $\mathrm{C}$ & 29,0 & 14,8 & 25,1 & 24,0 & 3,4 & 2,0 & 1,7 \\
\hline D & 49,2 & 18,0 & 26,0 & 2,7 & 1,2 & 1,2 & 1,6 \\
\hline$E$ & 27,2 & 14,7 & 42,9 & 4,1 & 3,2 & 4,2 & 3,6 \\
\hline $\mathrm{F}$ & 37,3 & 16,0 & 33,1 & 3,8 & 4,1 & 2,1 & 3,5 \\
\hline G & 32,5 & 15,6 & 38,5 & 4,4 & 5,2 & 1,8 & 2,2 \\
\hline $\mathrm{H}$ & 24,5 & 12,6 & 44,8 & 4,6 & 8,5 & 1,3 & 3,6 \\
\hline I & 24,9 & 13,0 & 49,3 & 3,6 & 4,2 & 2,5 & 2,7 \\
\hline 了 & 22,4 & 8,8 & 60,7 & 2,7 & 2,6 & 1,6 & 1,2 \\
\hline $\mathrm{K}$ & 23,2 & 9,3 & 57,8 & 2,5 & 3,6 & 1,3 & 2,0 \\
\hline$L$ & 22,0 & 13,4 & 45,7 & 6,2 & 3,4 & 3,4 & 3,5 \\
\hline$M$ & 32,1 & 18,4 & 36,9 & 5,1 & 3,8 & 2,0 & 1,7 \\
\hline $\mathrm{N}$ & 28,7 & 17,6 & 40,4 & 5,1 & 3,4 & 2,5 & 2,3 \\
\hline $\mathrm{O}$ & 24,3 & 12,3 & 49,8 & 4,1 & 4,2 & 2,4 & 2,9 \\
\hline $\mathrm{P}$ & 33,6 & 19,5 & 33,7 & 5,7 & 2,6 & 2,7 & 2,2 \\
\hline \multicolumn{8}{|l|}{$\%$ do } \\
\hline $\begin{array}{l}\text { emprego } \\
\text { regional }\end{array}$ & 34,4 & 16,7 & 35,8 & 4,5 & 3,6 & 2,2 & 2,5 \\
\hline
\end{tabular}

Unidade: Valores percentuais medios.

Fonte: Elaboração própria com base nas contas regionais.

Ramos: Agricultura (A); Pesca (B); Indústrias Extractivas (E); Indústrias Transformadoras (D); Electricidade, Gás e Água (E); Construção (F); Comércio e Outros (G); Alojamento e Restauração (H); Transportes e Comunicações (I); Actividades Financeiras (J); Imobiliário e Alugueres (K); Administração Pública, Defesa e Segurança Social (L); Educação (M); Saúde e Acção Social (N); Outros Serviços (O); Famílias com Empregados Domésticos ( $P$ ).

Quadro 2: Frequências relativas da distribuição sectorial do emprego por regiões no período 1995-2003

\begin{tabular}{|c|c|c|c|c|c|c|c|}
\hline \multirow[b]{2}{*}{ Ramos } & \multicolumn{7}{|c|}{ Regiões } \\
\hline & Norte & Centro & L.V. Tejo & Alentejo & Algarve & Açores & Madeira \\
\hline A & 10,8 & 17,1 & 4,4 & 20,1 & 10,5 & 21,7 & 15,2 \\
\hline B & 0,3 & 0,3 & 0,2 & 0,3 & 3,2 & 3,0 & 0,8 \\
\hline D & 30,6 & 22,4 & 13,8 & 11,4 & 5,7 & 9,1 & 11,5 \\
\hline $\mathrm{E}$ & 0,5 & 0,6 & 0,8 & 0,6 & 0,6 & 1,2 & 0,9 \\
\hline $\mathrm{F}$ & 10,4 & 9,1 & 8,7 & 8,0 & 10,5 & 9,2 & 14,1 \\
\hline $\mathrm{H}$ & 3,4 & 3,6 & 5,9 & 5,0 & 12,0 & 2,5 & 7,2 \\
\hline I & 2,4 & 2,6 & 4,4 & 2,6 & 3,9 & 3,7 & 3,7 \\
\hline ] & 1,5 & 1,2 & 4,0 & 1,4 & 1,6 & 1,8 & 1,1 \\
\hline $\mathrm{K}$ & 4,4 & 3,5 & 10,7 & 2,9 & 6,5 & 3,1 & 4,9 \\
\hline $\mathrm{L}$ & 4,9 & 6,2 & 10,4 & 11,1 & 7,3 & 12,8 & 12,0 \\
\hline$M$ & 5,9 & 6,9 & 6,4 & 7,0 & 6,7 & 5,4 & 4,2 \\
\hline
\end{tabular}

Unidade: Valores percentuais medios.

Fonte: Elaboração própria com base nas contas regionais.

Ramos: ver nota no Quadro 1.

A comparação com outras regiões torna ainda mais evidente a importância relativa que aqueles ramos assumem na região, já que ocupam cerca de $58,4 \%$ do emprego na região do Algarve, sendo o valor mais elevado do que nas restantes regiões. Aqueles ramos ocupam 38,4\% do emprego no Norte, 43,5\% no Centro, 34,4\% em Lisboa e Vale do Tejo, 26,9\% no Alentejo, 45,1\% nos Açores e $47,5 \%$ na Madeira. Verificamos assim que estes ramos provocam uma diferenciação da região algarvia, relativamente ao conjunto do país.

As regiões do Norte, Centro e Lisboa e Vale do Tejo caracterizam-se por uma actividade assente nas Indústrias Transformadoras (D) e no Comércio e Outros (G) que no conjunto ocupam $41,1 \%$, 33,5\% e 27,4\%, respectivamente. As regiões do Alentejo, Açores e Madeira assumem uma expressão significativa no ramo Agrícola (A), ao ocupar 18,1\%, 19,9\% e 13,8\% da força de trabalho respectivamente. 
Nesta seç̧ão são apresentados os resultados do Modelo de Base Económica. Embora o enfoque do artigo seja a região do Algarve, procede-se primeiramente a uma análise interregional com o objectivo de relativizar a posição da economia algarvia face às restantes regiões e, simultaneamente, enquadrar a análise dos resultados ao nível intra-regional, considerando os respectivos concelhos.

\section{ANÁLISE INTER-REGIONAL}

Os resultados obtidos para o emprego básico do conjunto das regiões Nuts II que constituem o país são apresentados no Quadro 3. Especificamente na região do Algarve, os ramos que registaram maior procura externa foram o Alojamento e Restauração (H), a Pesca (B), o Comércio e Outros (G), e a Construção (F). Neste período, foram ainda identificados outros ramos que contribuíram para o crescimento da economia da região, embora a uma escala mais reduzida, como sejam a Agricultura (A), as Indústrias Extractivas (C), os Transportes e Comunicações (I), o Imobiliário e Alugueres (K), a Educação (M), e os Outros Serviços (O).

Quadro 3: Valores médios do emprego básico no período 1995-2003

\begin{tabular}{|c|c|c|c|c|c|c|c|}
\hline \multirow{2}{*}{ Ramos } & \multicolumn{7}{|c|}{ Regiões } \\
\hline & Norte & Centro & L. V. Tejo & Alentejo & Algarve & Açores & Madeira \\
\hline Agricultura (A) & 5.818 & 89.585 & 0 & 14.323 & 253 & 6.471 & 3.673 \\
\hline Pesca (B) & 0 & 0 & 0 & 0 & 4.367 & 2.787 & 418 \\
\hline Indústrias Extractivas ( & 0 & 131 & 0 & 3.630 & 54 & 51 & 0 \\
\hline $\begin{array}{l}\text { Indústrias } \\
\text { Transformadoras (D) }\end{array}$ & 170.344 & 8.737 & 0 & 0 & 0 & 0 & 0 \\
\hline $\begin{array}{l}\text { Electricidade, Gás e Água } \\
\text { (E) }\end{array}$ & 0 & 0 & 2.321 & 7 & 0 & 602 & 429 \\
\hline Construção (F) & 14.589 & 0 & 0 & 110 & 2.559 & 813 & 6.185 \\
\hline Comércio e Outros (G) & 0 & 212 & 25.879 & 198 & 8.127 & 0 & 0 \\
\hline $\begin{array}{l}\text { Alojamento e } \\
\text { Restauração (H) }\end{array}$ & 0 & 0 & 13.524 & 1.506 & 17.471 & 68 & 4.007 \\
\hline $\begin{array}{l}\text { Transportes e } \\
\text { Comunicações (I) }\end{array}$ & 0 & 0 & 25.035 & 0 & 453 & 641 & 773 \\
\hline $\begin{array}{l}\text { Actividades Financeiras } \\
\text { (J) }\end{array}$ & 0 & 0 & 24.618 & 0 & 0 & 0 & 0 \\
\hline $\begin{array}{l}\text { Imobiliário e Alugueres } \\
(\mathrm{K})\end{array}$ & 0 & 0 & 62.652 & 0 & 266 & 0 & 55 \\
\hline $\begin{array}{l}\text { Admin. Púb., Def. e } \\
\text { Seg. Social (L) }\end{array}$ & 0 & 0 & 43.337 & 6.893 & 0 & 4.931 & 4.236 \\
\hline Educação (M) & 0 & 2.314 & 5.972 & 2.048 & 626 & 378 & 0 \\
\hline Saúde e Acção Social (N) & 0 & 2.651 & 9.784 & 3.028 & 0 & 1.230 & 0 \\
\hline Outros Serviços (O) & 0 & 0 & 24.344 & 0 & 1.367 & 51 & 784 \\
\hline $\begin{array}{l}\text { Famílias com Emp. } \\
\text { Domésticos }(P)\end{array}$ & 0 & 2.685 & 4.301 & 2.105 & 0 & 1.135 & 0 \\
\hline Total & 190.751 & 106.316 & 241.767 & 33.849 & 35.541 & 19.158 & 20.560 \\
\hline Multiplicador da base & 8.85 & 8.38 & 7.03 & 6.20 & 5.03 & 5.41 & 5.69 \\
\hline
\end{tabular}

Unidade: Numero de pessoas.

Fonte: Elaboração própria com base nas contas regionais. 
Estes resultados contrastam com os encontrados nas outras regiões, constituindo assim um elemento diferenciador da região do Algarve. Com efeito, as principais actividades básicas na região Norte são as Indústrias Transformadoras (D), a Construção (F) e a Agricultura (A); na região Centro são a Agricultura (A), as Indústrias Transformadoras (D) a Educação (M), a Saúde e Acção Social (N) e as Famílias com Empregados Domésticos (P); no Alentejo é a Agricultura (A), as Indústrias Extractivas (C), a Administração Pública, Defesa e Segurança Social (L), a Educação (M) a Saúde e Acção Social (N) e as Famílias com Empregados Domésticos (P); a região de Lisboa e Vale do Tejo é onde surge um maior número de actividades básicas, que englobam todos os ramos dos serviços; os Açores têm como principal actividade alvo de procura externa a Agricultura (A), a Pesca (B), a Administração Pública, Defesa e Segurança Social (L) e a Saúde e Acção Social (N); e a Madeira tem como actividades básicas a Construção $(F)$, o Alojamento e Restauração $(H)$, a Agricultura $(A)$ e a Administração Pública, Defesa e Segurança Social (L).

O Algarve diferencia-se assim das outras regiões do país como sendo aquela em que a Agricultura (A), a Indústria Transformadora (D) e a Administração Pública, Defesa e Segurança Social (L) não são catalisadores do crescimento económico. Pelo contrário, é a região com o maior número de empregos básicos no Alojamento e Restauração $(H)$ e na Pesca (B), ou seja, é a região onde estes ramos são alvo de maior procura externa. Constata-se ainda, que é a segunda região com maior número de empregos básicos nos ramos do Comércio e Outros (G) e do Imobiliário e Alugueres (K). Finalmente, a região posiciona-se na terceira posição do ranking nacional no que respeita ao número de empregos básicos na Construção (F), a seguir ao Norte e à Madeira, esta última outra região turística por excelência.

O cálculo dos multiplicadores da base demonstra que, no Algarve, cada emprego do ramo básico gerou, em média, 5,03 empregos no ramo não básico na economia, o valor mais baixo de todas as regiões. Isto significa, que o nível de fugas para o exterior da região é bastante mais elevado do que nas outras regiões. Esta situação pode ficar a dever-se a razões de vária ordem. Por um lado, pode ser explicado em parte pela pequena dimensão económica e geográfica da região e/ou pelo seu elevado grau de abertura. Contudo, outra possível explicação, pode assentar na ausência de uma indústria com raízes na própria região que satisfaça a procura interna, nomeadamente dos turistas que visitam a região, evitando assim a existência de saída de lucros por parte dos grupos económicos presentes na região mas com sede em outras regiões do país.

Quando se faz uma análise dinâmica verifica-se uma tendência crescente do Alojamento e Restauração $(\mathrm{H})$, como demonstra o Gráfico 1 , o que Ihe permitiu confiar a primeira posição em termos de criação de emprego básico na região. O ramo do Comércio e Outros (G) apresentou uma tendência decrescente, tendo consolidado a segunda posição em termos de emprego básico. A Pesca (B) detém a terceira posição e a Construção $(F)$ começou a apresentar alguma relevância a ponto de, no ano 2000, ter assumido a quarta posição em termos de emprego básico. 
Gráfico 1: Os ramos básicos no Algarve no período 1995-2003

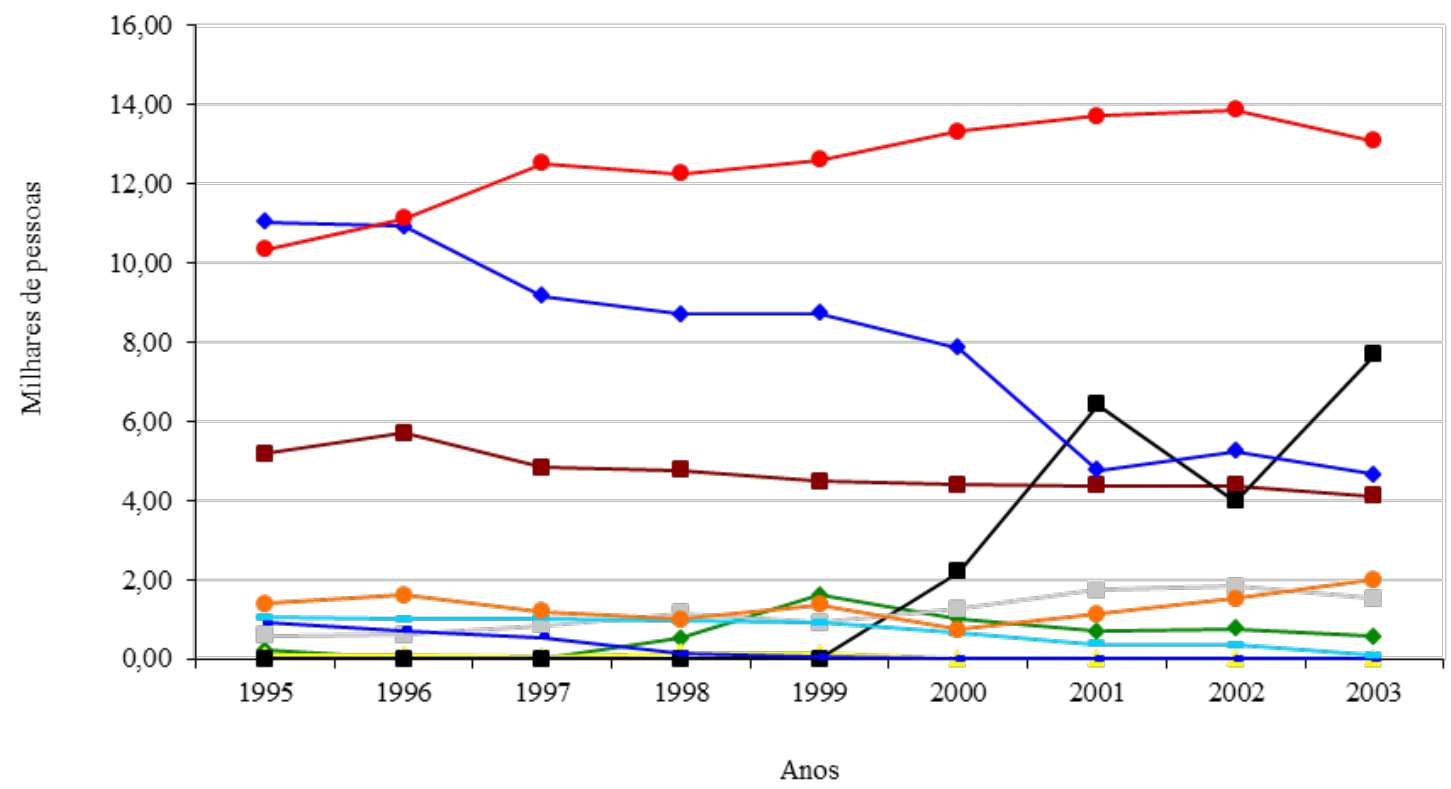

$$
\begin{aligned}
& \longrightarrow \text { Agricultura (A) } \rightarrow \text { Pesca (B) } \\
& \rightarrow \text { Construção (F) —Comércio e Outros (G) } \\
& \text { - Transportes e Comunicações (I) — Imobiliário e Alugueres (K) }
\end{aligned}
$$

Fonte: Elaboração própria com base nas contas regionais.

De uma forma geral, verifica-se que o emprego básico no Algarve cresceu $50 \%$, enquanto que o emprego não básico cresceu $21 \%$. Tal situação configura uma redução do multiplicador da base, 0 que significa que o grau de indução das actividades básicas sobre as não básicas decresceu durante o período estudado, como aliás se encontra patente no Quadro 4.

Quadro 4: Evolução do emprego básico e não básico no Algarve

\begin{tabular}{ccc}
\hline Anos & Emprego Básico & Emprego Não Básico \\
\hline 1995 & 30.575 & 129.225 \\
1996 & 31.734 & 131.066 \\
1997 & 30.121 & 131.379 \\
1998 & 29.599 & 136.901 \\
1999 & 30.730 & 141.770 \\
2000 & 38.020 & 141.080 \\
2001 & 41.529 & 146.271 \\
2002 & 41.856 & 152.044 \\
2003 & 45.710 & 156.290 \\
\hline
\end{tabular}

Unidade: Número de pessoas.

Fonte: Elaboração própria com base nas contas regionais.

Face aos dados, podemos concluir que os ramos que estiveram na base do crescimento da região, entre 1995 e 2003, foram o Alojamento e Restauração (H), a Pesca (B), o Comércio e Outros (G) e a Construção (F), embora o seu grau de indução sobre as actividades não básicas se tenha reduzido, o que se reflectiu numa redução do multiplicador da base, que por si já é mais baixo do que nas restantes regiões. Este resultado significa que o Algarve não conseguiu estimular os seus ramos de actividade através da sua base de exportação. 
ANÁLISE INTRA-REGIONAL

Após a identificação dos ramos geradores de emprego básico, torna-se útil analisar a sua distribuição geográfica. Os resultados encontram-se no Quadro 5. Observa-se que os ramos identificados concentram-se essencialmente na pequena faixa litoral compreendida entre os concelhos de Portimão e Olhão. Concretamente o ramo do Alojamento e Restauração $(H)$ assume a sua expressão máxima nos concelhos de Albufeira, Loulé e Portimão; o ramo do Comércio e Outros (G) destaca-se nos concelhos de Faro, Loulé, Olhão e Portimão; o ramo da Pesca (B) assume maior relevo nos concelhos de Loulé e Olhão; e o ramo da Construção $(F)$ assume maior importância relativa nos concelhos de Faro, Loulé e Portimão.

A análise permite assim concluir sobre a estrutura económica dos concelhos em termos de ramos básicos. Em particular, os concelhos de Faro, Portimão e Loulé apresentam uma estrutura económica assente num elevado número de ramos básicos, ao contrário do que acontece nos concelhos de Albufeira, Lagos, Olhão, Silves e Tavira cujas economias assentam num reduzido número de ramos exportadores. Os restantes concelhos têm economias constituídas somente por ramos não básicos. 


\begin{tabular}{|c|c|c|c|c|c|c|c|c|c|c|c|c|c|c|c|c|}
\hline 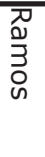 & & & & & & & & & 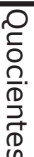 & & & & & & & \\
\hline & $\begin{array}{l}\frac{D}{\bar{D}} \\
\bar{C} \\
\frac{\vec{D}}{\bar{a}}\end{array}$ & $\begin{array}{l}\frac{D}{2} \\
\frac{0}{\frac{1}{5}} \\
\frac{\bar{J}}{.}\end{array}$ & $\begin{array}{l}\underset{D}{\mathbb{D}} \\
\stackrel{N}{\subseteq}\end{array}$ & 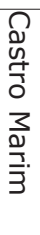 & $\begin{array}{l}\text { 刃्ग } \\
\stackrel{2}{0}\end{array}$ & $\begin{array}{l}\Gamma \\
0 \\
0 \\
0 \\
0\end{array}$ & $\begin{array}{l}\Gamma \\
\tilde{0} \\
0 \\
\text { ஸे }\end{array}$ & 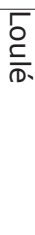 & 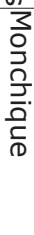 & 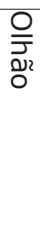 & 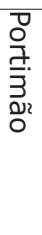 & 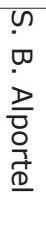 & $\frac{\omega}{\bar{N}}$ & 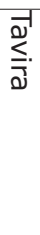 & $\begin{array}{l}< \\
\frac{0}{0} \\
\frac{0}{0} \\
0\end{array}$ & 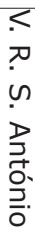 \\
\hline$D$ & 0 & 0 & 0 & 0 & $\underset{\omega}{\omega}$ & 0 & 0 & $\underset{\omega}{N}$ & 0 & 0 & 0 & 0 & $\stackrel{\vec{P}}{\overrightarrow{0}}$ & $\underset{N}{N}$ & 0 & 0 \\
\hline రు & 0 & 0 & 0 & 0 & 0 & 0 & 0 & $\vec{v}$ & 0 & $\stackrel{\text { I্ }}{ }$ & 0 & 0 & 0 & $\underset{\infty}{N}$ & 0 & 0 \\
\hline$\cap$ & 0 & 0 & 0 & 0 & ब & 0 & 0 & $\stackrel{M}{\triangle}$ & 0 & $\stackrel{\sim}{\omega}$ & 0 & 0 & 0 & 0 & 0 & 0 \\
\hline$\nabla$ & 0 & 0 & 0 & 0 & $\underset{\triangleright}{\stackrel{Ð}{\circ}}$ & 0 & 0 & $\underset{\omega}{\stackrel{\rightleftharpoons}{\omega}}$ & 0 & $\underset{\sim}{\stackrel{\sigma}{w}}$ & $\mathrm{~N}$ & 0 & 0 & 0 & 0 & 0 \\
\hline $\mathrm{m}$ & 0 & 0 & 0 & 0 & • & 0 & 0 & 은 & 0 & $\underset{\perp}{\omega}$ & $\underset{\perp}{\sim}$ & 0 & 0 & 0 & 0 & 0 \\
\hline$\pi$ & 0 & 0 & 0 & 0 & $\stackrel{W}{D}_{D}^{w}$ & 0 & 0 & $\stackrel{⿱ ⺊}{\stackrel{\infty}{N}}$ & 0 & ${ }^{\omega}$ & $\stackrel{్}{\omega}$ & 0 & के & 0 & 0 & 0 \\
\hline ๑ & 0 & 0 & 0 & 0 & 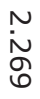 & 0 & 0 & $\begin{array}{l}\text { N } \\
\stackrel{\circ}{\circ}\end{array}$ & 0 & $\stackrel{\infty}{\infty}$ & 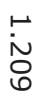 & 0 & $\stackrel{\vec{\omega}}{\omega}$ & 0 & 0 & 0 \\
\hline$I$ & $\begin{array}{l}\text { un } \\
\text { ڤ̆ }\end{array}$ & 0 & 0 & 0 & 0 & 0 & 0 & $\stackrel{\sim}{*}$ & 0 & 0 & $\begin{array}{l}+ \\
\dot{\alpha} \\
\stackrel{N}{N}\end{array}$ & 0 & 0 & 0 & 0 & 0 \\
\hline$\mapsto$ & 0 & 0 & 0 & 0 & $\stackrel{\bullet}{\tilde{N}}$ & 0 & 0 & 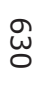 & 0 & 0 & $\stackrel{\infty}{N}$ & 0 & 0 & 0 & 0 & 0 \\
\hline$\bullet$ & 0 & 0 & 0 & 0 & $\stackrel{\vec{f}}{\circ}$ & 0 & 0 & $\underset{\omega}{\omega}$ & 0 & 0 & $\stackrel{⿱ ⺊ 尸}{N}$ & 0 & 0 & 0 & 0 & 0 \\
\hline$\pi$ & 0 & 0 & 0 & 0 & $\stackrel{\bullet}{v}$ & 0 & 0 & $\begin{array}{l}\stackrel{\bullet}{\circ} \\
\stackrel{\circ}{v}\end{array}$ & 0 & $\stackrel{\infty}{\infty}$ & $\underset{\omega}{\sim}$ & 0 & 0 & 0 & 0 & 0 \\
\hline\ulcorner & 0 & 0 & 0 & 0 & $\begin{array}{l}\mathfrak{u}^{\prime} \\
\stackrel{\infty}{v}\end{array}$ & 0 & 0 & $\stackrel{t}{\mathrm{v}}$ & 0 & 0 & $\triangleright$ & 0 & 0 & 0 & 0 & 0 \\
\hline 3 & 0 & 0 & 0 & 0 & 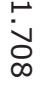 & 0 & 0 & $\underset{\omega}{\omega}$ & 0 & N & 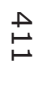 & 0 & 0 & 0 & 0 & 0 \\
\hline$z$ & 0 & 0 & 0 & 0 & $\underset{\omega}{\omega}$ & 0 & 0 & 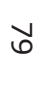 & 0 & $\stackrel{v}{v}$ & $\underset{\omega}{\mathcal{W}}$ & 0 & 0 & 0 & 0 & 0 \\
\hline 0 & 0 & 0 & 0 & 0 & $\underset{\sim}{\omega}$ & 0 & 0 & $\stackrel{+}{\infty}$ & 0 & 0 & $\stackrel{\stackrel{N}{N}}{ }$ & 0 & 0 & 0 & 0 & 0 \\
\hline$\nabla$ & 0 & 0 & 0 & 0 & $\stackrel{N}{\stackrel{2}{a}}$ & 0 & 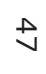 & $\underset{\perp}{\omega}$ & 0 & 0 & t & 0 & 0 & 0 & 0 & 0 \\
\hline $\begin{array}{l}\text { 우 } \\
\underline{+}\end{array}$ & $\begin{array}{l}\text { N } \\
\text { ơ } \\
\end{array}$ & 0 & 0 & 0 & $\begin{array}{l}\stackrel{\sim}{N} \\
\stackrel{0}{0} \\
\text { O }\end{array}$ & 0 & $\stackrel{ \pm}{v}$ & $\begin{array}{l}\text { ! } \\
\stackrel{2}{N} \\
\text { N }\end{array}$ & 0 & 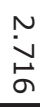 & $\begin{array}{l}\text { r } \\
\tilde{N} \\
0\end{array}$ & 0 & $\underset{\infty}{N}$ & $\underset{v}{N}$ & 0 & 0 \\
\hline
\end{tabular}

Unidade: Numero de pessoas.

Fonte: Elaboração própria com base nos censos.

Ramos: Agricultura (A); Pesca (B); Indústrias Extractivas (E); Indústrias Transformadoras (D); Electricidade, Gás e Água (E); Construção (F); Comércio e Outros (G); Alojamento e Restauração (H); Transportes e Comunicações (I); Actividades Financeiras (J); Imobiliário e Alugueres (K); Administração Pública, Defesa e Segurança Social (L); Educação (M); Saúde e Acção Social (N); Outros Serviços (O); Famílias com Empregados Domésticos $(P)$. 
A análise aponta assim no sentido de uma economia regional bastante terciarizada, onde os ramos exportadores concentram-se num reduzido número de concelhos, que possuem uma estrutura económica directamente ligada ao turismo, através do ramo do Alojamento e Restauração $(H)$ e indirectamente, através dos ramos do Imobiliário e Alugueres (K) e do Comércio e Outros (G).

\section{CONCLUSÕES}

Este trabalho teve como objectivo central identificar os ramos que têm estado na base do crescimento da região do Algarve, nomeadamente estabelecendo a distinção entre os ramos básicos, ou exportadores, e os ramos não básicos ou dirigidos à satisfação das populações nacionais.

Foi adoptado o modelo da Base Económica, numa análise desenvolvida aos níveis interregional e intra-regional que permitiu identificar factos estilizados relevantes. Por um lado, os resultados sugerem que os ramos que estiveram na base do crescimento da região, entre 1995 e 2003, foram o Alojamento e Restauração, ramo directamente ligado ao turismo e a Pesca, o Comércio e Outros e a Construção, que representam ramos com ligações indirectas à actividade turística, embora o seu grau de indução sobre as actividades não básicas se tenha reduzido. Tal situação reflectiu-se numa redução do multiplicador da base, o qual já é mais baixo do que nas restantes regiões. Este resultado significa que o Algarve não conseguiu estimular os seus ramos de actividade através da sua base de exportação. No geral a análise demonstra que a economia regional é bastante terciarizada e o emprego básico encontra-se essencialmente nos concelhos com freguesias litorais, entre Lagos e Faro, que possuem uma estrutura económica directamente ligada ao turismo através do ramo do Alojamento e Restauração e indirectamente, através dos ramos do Imobiliário e Alugueres e do Comércio e Outros.

Os resultados expostos suscitam a questão da possível especialização da região do Algarve num número de sectores relativamente reduzido o que potencia a fragilidade da sua economia. No entanto, a análise detalhada desta questão está fora do âmbito deste estudo e constituirá um tema para futura investigação.

\section{REFERÊNCIAS}

CABRAL, M. D.; SOUSA, R. Indicadores de localização, especialização e diversificação e análise Shift-Share: uma aplicação às NUTS III da região Norte no período 1986-1998. Núcleo de investigação em políticas económicas, Universidade do Minho, 2001.

CARVALHO, H. Tipologia e padrões de localização da indústria transformadora em Portugal Continental: análise Shift-Share 1971-1988. Tese de Mestrado, Universidade de Coimbra, Faculdade de Letras, 1992.

DELGADO, A. P. e GODINHO, I. M. "Medidas de localização das actividades e de especialização regional". In: COSTA, J. S. Compêndio de Economia Regional. APDR: Coimbra, p. 723-742, 2002.

DOUGLASS, C. N. "Location Theory and Regional Economic Growth". Journal of Political Economy, University of Chicago Press, vol. 63, p. 243-258, 1955.

HOYT, H. The structure and growth of residential neighborhoods in American cities. Washington, DC: Federal Housing Administration, 1939.

INSTITUTO Nacional de Estatística. Contas regionais 1995-98 e estimativas Preliminares de 1999. Lisboa, 2001.

INSTITUTO Nacional de Estatística. Quadros de resultados - Contas regionais por ramos de actividade (1995 a 2001). Disponível em: < http://www.ine.pt/prodserv/quadros/036/173/003/pdf/Capitulo3.pdf $\geq$ Acesso em: 28 de Janeiro de 2009.

INSTITUTO Nacional de Estatística. Emprego total, por região NUTS I e II, segundo a classificação de actividades A17 (2001 a 2002). Disponível em: <http://www.ine.pt/prodserv/quadros/036/215/001/ xls/00700000.xls> Acesso em: 28 de Janeiro de 2009.

INSTITUTO Nacional de Estatística. Emprego total, por região NUTS I e II, segundo a classificação de actividades A17 (2003). Disponível em: <http://www.ine.pt/prodserv/quadros/036/218/001/xls/00700000. xIs> Acesso em: 28 de Janeiro de 2009. 
SILVA, J. A. e ANDRAZ, J. M. "O padrão de especialização e a localização das actividades económicas na região do Algarve". Estudos I. Universidade do Algarve, Faculdade de Economia, p. 177-194, 2004.

TIEBOUT, C. "A Pure Theory of Local Expenditures". Journal of Political Economy, v. 64, n. 5, p. 416-424, 1956.

WORLD TRAVEL AND TOURISM COUNCIL. The Algarve: The impact of travel \& tourism on jobs and the economy. Disponível em: http://www.wttc.org/bin/ pdf/ original_pdf_file/algarve2003.pdf>. Acesso em: 7 de Agosto de 2009.

ZUCATTO, L. C.; FERASSO, M. e EVANGELISTA, M. L. S. "A Importância das Exportações para o Desenvolvimento Local da Fronteira Noroeste do Rio Grande do Sul e do Extremo-Oeste de Santa Catarina - Um Estudo de Caso". Simpoi Anais: sl., 2008.

Data de Submissão: 05/09/2011

Data de Aprovação: 31/10/2012 